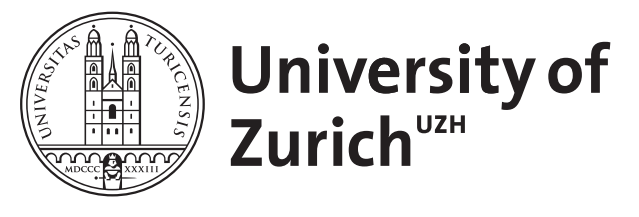

\title{
A developmental perspective on moral emotions
}

\author{
Malti, T ; Dys, Sebastian P
}

\begin{abstract}
This article outlines a developmental approach to the study of moral emotions. Specifically, we describe our developmental model on moral emotions, one in which emotions and cognitions about morality get increasingly integrated and coordinated with development, while acknowledging inter-individual variation in developmental trajectories across the lifespan. We begin with a conceptual clarification of the concept of moral emotions. After a brief review of our own developmental approach to the study of moral emotions, we provide a selective summary of the developmental literature on negatively and positively valenced moral emotions, and describe a recent line of developmental research on the anticipation of negatively and positively valenced moral emotions in multifaceted contexts of social exclusion and inclusion. Next, we describe what it means to take a developmental perspective on moral emotions. Finally, we provide some preliminary conclusions and recommendations for future work to the developmental study of moral emotions.
\end{abstract}

DOI: https://doi.org/10.1007/s11245-013-9224-5

Posted at the Zurich Open Repository and Archive, University of Zurich

ZORA URL: https://doi.org/10.5167/uzh-87084

Journal Article

Accepted Version

Originally published at:

Malti, T; Dys, Sebastian P (2015). A developmental perspective on moral emotions. Topoi: An International Review of Philosophy, 34(2):453-459.

DOI: https://doi.org/10.1007/s11245-013-9224-5 


\title{
RUNNING HEAD: DEVELOPMENTAL PERSPECTIVE ON MORAL EMOTIONS
}

\section{A Developmental Perspective on Moral Emotions}

\author{
Tina Malti and Sebastian P. Dys \\ University of Toronto
}

\section{Author Note}

Tina Malti, Department of Psychology, University of Toronto; Sebastian Paul Dys, Department of Psychology, University of Toronto.

This research was funded by the Social Sciences and Humanities Research Council of Canada. Special thanks and appreciation go to the Research Assistants at the Laboratory for Social-emotional Development and Intervention at the University of Toronto, to the families, teachers, and practitioners who dedicated their time to participate in our research, and to our research collaborators.

Correspondence concerning this article should be addressed to Tina Malti, Department of Psychology, University of Toronto, 3359 Mississauga Road North, Missisauga, ON L5L 1C6, Canada. Electronic mail may be sent to tina.malti@utoronto.ca

\section{Topoi}

In Press 


\begin{abstract}
This article outlines a developmental approach to the study of moral emotions. Specifically, we describe our developmental model on moral emotions, one in which emotions and cognitions about morality get increasingly integrated and coordinated with development, while acknowledging inter-individual variation in developmental trajectories across the lifespan. We begin with a conceptual clarification of the concept of moral emotions. After a brief review of our own developmental approach to the study of moral emotions, we provide a selective summary of the developmental literature on negatively and positively valenced moral emotions, and describe a recent line of developmental research on the anticipation of negatively and positively valenced moral emotions in multifaceted contexts of social exclusion and inclusion. Next, we describe what it means to take a developmental perspective on moral emotions. Finally, we provide some preliminary conclusions and recommendations for future work to the developmental study of moral emotions.

Keywords: Moral emotions; guilt, developmental model; childhood; adolescence
\end{abstract}




\section{A Developmental Perspective on Moral Emotions}

Moral emotions have recently regained considerable attention in various disciplines, including philosophy, psychology, neuroscience, economy, genetics, and sociology (e.g., Sinnott-Armstrong, 2008a, 2008b). Unsurprisingly, there has also been an upswell of interest around the moral emotions in the development science literature. From a developmental perspective, some of the most puzzling questions around human moral emotions are about their emergence, development, and their integration and increasing coordination with advancements in social-cognitive development. The aim of this article is to describe a developmental perspective on the study of moral emotions, which entails dynamic processes of change and stability in emotion and relayed cognition across development. We will also provide a selective review of the developmental research on moral emotions and provide recommendations for promising future avenues to the developmental study of moral emotions.

What makes a developmental approach to moral emotions distinct from other psychological perspectives on human emotions? A developmental perspective puts explicit emphasis on an understanding of the processes of change, both across individuals and across time. They provide answers to questions like what kind of continuities and discontinuities can be observed across time in the occurrence and intensity of emotions in contexts of everyday morality, why do these changes or stabilities occur, and how do they predict other dimensions of social-emotional development. Typically, this involves the nomothetic study of normative change in moral emotions for example by a comparison between age groups (such as early vs. middle childhood). The choice of specific age groups is theoretical in nature and requires reflection about developmental milestones and achievements such as children's increasing understanding of others mind, intentions, and complex emotions. Change in emotions is neither 
always meaningful nor static. Rather, it involves dynamic processes that may be described as linear growth, linear decline, or nonlinear patterns of change. It also includes the study of changing relationships between different types of emotions over time. Thus, the developmental study of moral emotions entails an investigation of normative changes in the occurrence of particular moral emotion(s), which is often, but not always, age-related. Empirically, developmental studies on moral emotions have frequently utilized cross-sectional designs to compare differences in the expression of moral emotions across age groups. Thus far, the use of longitudinal studies to examine moral emotions, albeit of central significance to understand patterns of intra-individual change in moral emotions, has been rather limited, with the exception of the morally relevant process of empathy/sympathy (Eisenberg, Spinrad, \& Morris, in press) and early forms of guilt (Kochanska, Gross, Lin, \& Nichols, 2002).

Until a decade ago, developmental studies on morality have been dominated by the cognitive-developmental tradition, in light of the influential writings of Piaget $(1932,1999)$, Kohlberg (1984) and Turiel (1983). This tradition has made major contributions to our understanding of moral reasoning. However, it has neglected the systematic study of emotions and their role in children's morality. Thus many questions surrounding how children come to treat moral norms as personally binding and obligatory were left unanswered. Developmental researchers clearly felt an increasing urge to investigate what motivates children to act in accord with moral principles. This was, in part, due to the fact that no strong link between moral reasoning and moral action was found (Blasi, 1980). Emotions were a prominent candidate for further investigation, as emotions matter to us and may therefore serve as an important motive for moral action tendencies (Malti, Gummerum, Keller, \& Buchmann, 2009). There was also increasing recognition that even young children are voluntarily able to express concern for 
others and care about needy others (Hoffman, 2000), which led developmental scientists to an increasing interest in, and study of, the role of emotions in children's emerging and developing morality.

\section{What are Moral Emotions?}

Moral emotions have been defined as self-evaluative, self-conscious or other-oriented emotions in response to morally salient situations as they either presuppose an evaluation of one's own actions in relation to the consequences they have on others (e.g., leading to guilt), or an appreciation (or apprehension) for another's emotional state (e.g., leading to sympathy; Eisenberg, 2000; Tangney, Stuewig, \& Mashek, 2007). Thus, moral emotions are elicited by one's evaluative judgments and appraisals (Nussbaum, 2001). Though moral emotions and cognitions are closely related, as the evocation of former is dependent on the latter, the two facets are distinguishable as emotions enact motivational forces, while cognitions engage knowledge structures (Izard, 1994; Malti \& Ongley, 2013). Prototypical negatively valenced moral emotions are guilt, shame, and compassion, whereas prototypical positively valenced moral emotions are pride, gratitude, and elevation (Malti \& Latzko, 2012; Tracy, Robins, \& Tangney, 2007).

Moral emotions are necessary for moral action as without experiencing or anticipating moral emotions, moral knowledge can be strategically used to manipulate others in order to achieve selfishly motivated goals (Gasser \& Keller, 2009). We argue that moral emotions are complex emotions, which unlike basic emotions, necessarily involve a substantial degree of cognitive processing. These emotions developmentally presuppose at least a basic understanding of the other's mind and understanding about why it is wrong to break moral norms of fairness, justice, and care (Malti \& Ongley, 2013; Malti \& Keller, 2010). Research has 
provided evidence for the role of morally relevant thought in making moral judgments (e.g., the intentions of an actor; Leslie, Knobe, \& Cohen, 2006; Killen, Mulvey, Richardson, Jampol, \& Woodward, 2011). Furthermore, neuroscience research has documented that emotion and cognition are inherently connected in moral situations in the brain (Blair \& Fowler, 2008; Decety, Michalska, \& Kinzler, 2012). Thus, with development, emotions in the context of morality may become increasingly tied to an inner world of mental states shared with other people (Carpendale \& Lewis, 2006; Lagattuta \& Thompson, 2007), which may give rise to more complex emotions, such as guilt. Guilt, in turn, has been shown to predict morally relevant behavior (Malti \& Krettenauer, 2013).

\section{Developmental Research on Moral Emotions}

Developmental research on moral emotions has predominantly focused on the morally relevant processes of empathy and sympathy (for a review, see Eisenberg et al., in press). This research has provided evidence that the first precursors to empathy, the apprehension of another's emotional state, are evident in infants as well as some primates (Flack \& de Waal, 2000). In the first year of life, the ability to distinguish between the self and the other is an important developmental milestone that contributes to the development of empathy (Hoffman, 2000). The emergence of sympathy, which entails a feeling of sorrow for another (but, unlike empathy, does not necessarily involve mimicking their emotional state) and an understanding of their circumstance, emerges later (Eisenberg et al., 2006) and continues to develop throughout childhood and adolescence (Carlo, 2006; Malti, Gummerum, Keller, Chaparro, \& Buchmann, 2012). What is much less known, though, are how other moral emotions develop. To date, developmental studies on guilt and other negatively moral emotions remain scarce, and long- 
term longitudinal data are even rarer. There are even fewer developmental studies on positively valenced moral emotions.

Kochanska and colleagues have investigated early forms of guilt, as well as its antecedents and outcomes (e.g., Kochanska, Barry, Jimenez, Hollatz, \& Woodard, 2009). In our own work, we have investigated the development of guilt feelings from early childhood to young adulthood using both cross-sectional and longitudinal designs. This developmental research began with the cross-sectional study of emotions in the context of hypothetical moral transgressions. The original focus was on the anticipation of emotions to protagonists in response to hypothetical moral transgressions, such as stealing another child's chocolate or pushing another child off the swing. The anticipation of negative emotions, such as sadness, guilt, or bad feelings, has been interpreted as an empirical indicator of guilt feelings (Malti et al., 2009). The classic study by Nunner-Winkler \& Sodian (1988) documented that 8-year-olds were more likely to anticipate negative feelings to the transgressor than are 4-year-olds. This shift from positive to negative attributions has been labelled the "happy victimizer phenomenon" and replicated in various studies from Europe, the US, South America, and China (for reviews, see Arsenio, in press; Krettenauer, Malti, \& Sokol, 2008).

More recently, we have extended this body of research further by investigating guilt feelings longitudinally. For example, in a study with a Swiss sample of 175 6-year-old children who were reassessed at 7 and 9 years of age, we found that most children followed a high-stable trajectory of guilt (69\%). However, another group of children showed an increase in guilt feelings over time (20\%), and a third group of children showed a decrease in guilt feelings over time (11\%; Malti, Eisenberg, Kim, \& Buchmann, 2013). 
Another recent body of work has focused on children's and adolescents' positively valenced moral emotions, such as pride. This line of work shows that many adolescents, when having a choice between a moral and an amoral choice, chose to behave morally and anticipate positively valenced moral emotions (i.e., the happy moralist pattern), although some who chose to behave morally anticipated negative emotions (i.e., the unhappy moralist pattern). The agerelated differences for positively valenced moral emotions have mirrored the findings for negatively valenced emotions as they have been shown to increase with age from midchildhood to early adulthood (Oser, 2006; Malti, Keller, \& Buchmann, 2012).

We have recently also begun to extend this theoretical approach to moral emotions by including new measures that tap into more spontaneous emotional reactions towards transgressions. Spontaneous emotions (also known as microexpressions) are rapid and often unconscious emotional expressions which last for a fraction of a second (Ekman \& Friesen, 1969), thus, unlike self-reported emotions, temporally precede self-reported intentional cognitive thought. In conjunction with self-reported emotions, they can provide insight into the roles of automatic affective and intentional cognitive processes in moral development. We used innovative emotion recognition technology (Noldus's Facereader 4.0), which uses facial expressions to classify basic emotional reactions, to study the spontaneous emotional expressions of 242 4-, 8- and 12-year-olds' in response to moral transgressions and asked them about their self-reported emotions (Dys and Malti, 2013). We found that children's levels of spontaneous expressions of sadness were lowest for 4-year-olds, and increased for 8- and 12year-olds. Meanwhile, levels of spontaneous happiness amongst 4- and 8-year-olds were comparable, though higher than those of 12-year-olds. Additionally, in line with traditional happy victimizer research, we found that 8-year-olds reported more negative (and fewer 
positive) emotions than 4-year-olds. But, then why might 8-year-olds still show more spontaneous expressions of happiness?

We interpreted these findings to suggest that intentional cognitive thought was responsible for the shift from positive (i.e., immoral) emotional reactions to negative (i.e., moral) emotions.. For example, some 8-year-olds may initially react to the positive outcomes of a moral transgression, such as getting to eat a chocolate bar one steals from a classmate, but then shift their attention toward considering the influence of their actions on the victim. Furthermore, the coherence between spontaneous and self-reported emotions for 12-year-olds suggests that early adolescents generally do not spontaneously react to the positive aspects, instead immediately responding to the negative aspects, of moral transgressions. We believe this shift toward negative spontaneous emotions in 12-year-olds may be a product of previous cognitive coordination processes. In other words, we suggest that as children extensively exercise this coordination process in middle childhood, the resulting cognitively infused emotions may become internalized to the point that they are reflected in automatic, spontaneous emotional reactions. Thus, we took the findings of this study as support for our notion of the interconnectedness between affective and cognitive factors in morality.

\section{Developmental Research on Emotions in Contexts of Social Exclusion}

Another recent line of work has extended the study of emotions in contexts of straightforward moral transgression to children's and adolescents' anticipation of moral emotions in multifaceted situations of social exclusion and inclusion. These contexts are typically more complex and require the balancing of group norms and group functioning with moral considerations of fairness and care (Killen, 2007; Killen, Lee-Kim, McGlothlin, \& Stangor, 2002). As such, these contexts are likely to represent children's real-life experiences of 
moral and social conflict. Although not many studies have investigated the development of emotions in these contexts, the existing findings indicate a more complex picture of the development of moral emotions. For example, a study on children's emotions in contexts of exclusion of children with different disabilities found an expected developmental increase in the anticipation of moral emotions, such as guilt, to excluders, from 6 to 12 years of age (Gasser, Malti, \& Buholzer, 2013).

In a study on emotions in 12- and 16-year-old adolescents following social exclusion, the findings revealed that adolescents do frequently attribute moral emotions, such as guilt and sadness, to excluders. However, they also attribute amoral emotions, such as happiness and pride, to excluders, for reasons of group functioning. No age differences were observed (Malti, Killen, \& Gasser, 2012). Taken together, these findings indicate that multifaceted social situations elicit a variety of different, sometimes conflicting moral and amoral emotions in young people. There is also evidence that the types of emotions anticipated in these contexts depend on group dynamics, as well as the interplay between group dynamics and development. This research has revealed that emotions associated with experiences of social exclusion can be altered in the presence of bystanders. For example, in a study by Strohmeier, Malti, and Killen (2013), 12- and 16-year-old adolescents responded to film vignettes depicting everyday exclusion experiences in the school context. The vignettes varied as a function of bystander behavior: either there was no bystander, an on-looking bystander (who did not invite the excluded child to join them), or an integrating bystander (who invited the child to join them). It was found that adolescents anticipated more happiness and pride in excluders when bystanders were present than when there were no bystanders. Interestingly, 16-year-olds anticipated more fear and empathy in the integrating bystander condition than 12-year-olds. In contrast, 12-year- 
olds anticipated more positive emotions in the integrating bystander condition than 16-yearolds. Adolescents may increasingly understand group dynamics with age, and they may understand the feelings of the victim, which is why they anticipate empathy, but also anticipate the potentially negative consequences on their relationships with other peers following the inclusion of an out-group member. This may be the reason why they may anticipate more fear in the integrating bystander condition. Therefore, the anticipation of both moral and amoral emotions may indicate that they have a more nuanced understanding of the psychological harm associated with exclusion, but also that situations involving social exclusion involve conflicting moral and social-conventional considerations (Smetana, 2006).

\section{A Developmental Perspective on Moral Emotions}

We have proposed an integrative developmental model to describe the development of moral emotions (Malti \& Keller, 2010; Malti \& Ongley, 2013). Accordingly, there are normative developmental changes in children's and adolescents' anticipations of negatively valenced moral emotions, particularly guilt. These changes are accompanied by, and increasingly integrated with, moral and social knowledge. At the same time, these normative changes are constrained by inter-individual variations, which are associated with various psychological, biological, and social differences. For example, research has shown that there is a genetic effect on children's empathy at 24 and 36 months of age (Knafo, Zahn-Waxler, Van Hulle, Robinson, \& Rhee, 2008).

We have interpreted the development of moral emotions in the framework of an affectcognition model (Malti, 2013), which interconnects moral emotions with moral reasoning and children's social understanding (see Malti \& Keller, 2010; Malti \& Ongley, 2013). This is based on the theoretical notion proposing that the presence of moral emotions requires some 
basic social understanding, and the endorsement of moral norms is enforced through the internalization of other-oriented or self-evaluative emotions (Gibbard, 1990). Although even infants may display basic emotional reactions in response to moral transgressions at an early age, these emotions would only be considered to be precursors to complex, moral emotions. Accordingly, moral emotions can provide an early foundation for the development of moral awareness because they indicate that the self feels committed to a norm (Johnston \& Krettenauer, 2011; Malti et al., 2009). Although even young children are genuinely concerned with others' welfare, they often have difficulties connecting their concern for others' perspectives to their moral emotions and reasoning (Wainryb, Brehl, \& Matwin, 2005). The early precursors of morality might be what has been called a "theory of agency", which involves an understanding that individuals are free to behave in congruence with moral norms, and that those have who have committed moral transgressions have disregard these norms (Sokol, 2004). This process entails coordination between moral emotions, reasoning, and the consequences of children's action in relation to others (Krettenauer et al., 2008. Through social interactions children increasingly come to understand social and moral norms and individuals' agency to act in congruence with these norms.. Affectively, children are increasingly able to anticipate empathy or guilt as a consequence and relation of one's own actions on others. Various social-cognitive prerequisites for the development of moral emotions have been considered, such as an interpretive theory of mind or an understanding of mixed emotions (Sokol \& Chandler, 2003; see Carpendale \& Lewis, 2006). Thus, our model describes three processes of development. First, children first learn to distinguish between the self and others at a time when they also become aware that moral transgressions have negative consequences for victims. However, these consequences are not taken into account emotionally, thus leading to 
the happy victimizer phenomenon (Malti \& Keller, 2010). Second, when children learn to coordinate the two perspectives, they realize that transgressions not only have negative effects on others but also to the self, which elicits negative feelings, such as guilt. Finally, by late childhood or early adolescence, children increasingly develop a meta-perspective, including the ability to reflect upon how one ought to treat others to establish and maintain trust in social interactions. Negatively valenced moral emotions emerge when the person violates this trust, while positively valenced moral emotions are a result of being in accord with one's moral ideals (Malti \& Keller, 2010).

In summary, our model assumes that emotions are based on the ability to take and coordinate the perspective of self and other, but that this form of social understanding is a necessary but insufficient condition for the development of complex moral emotions. In addition, moral emotions and moral reasoning become increasingly coordinated and integrated with development. While the model expects normative changes in the anticipation of moral emotions across the life course, it also acknowledges discontinuity and inter-individual variation in the anticipation of moral emotions (see Arsenio, in press; Krettenauer \& Eichler, 2006; Malti \& Krettenauer, 2013), which may occur for example due to behavioral problems in children (Frick \& White, 2008). The model is constructivist in that acknowledges that even young children actively construct moral knowledge, intentions, and associated emotional consequences in continuous interaction with others. Research has shown that children are able to make moral judgments, express spontaneous empathic concern, and engage in pro-social behaviors from early on (e.g., Davidov, Zahn-Waxler, Roth-Hanania, \& Knafo, 2013; Knafo \& Plomin, 2006; Roth-Hanania, Davidov, \& Zahn-Waxler, 2011; Turiel, 1983). Yet, the development of moral emotions is a lifelong process, and many of the more complex moral 
emotions and integrative affect-reasoning processes do not yet exist in early childhood. The reasons for, and meaning of, the discrepancies between affect and cognition in moral encounters may change with development as well: for example, while discrepancies between moral rule knowledge and emotional reactions to transgressions may relate to cognitive constraints in early childhood (although even infants understand the basic distinction between "bad" and "good"; Hamlin, Wynn, Bloom, 2007), other factors, such as motivational differences or situational complexity, may interact with, and potentially alter, normative change in multifaceted ways.

\section{Conclusions}

The main aim of this article was to describe a developmental perspective on moral emotions, one which systematically integrates affect and cognition in the emergence, and development, of more complex moral emotions. Developmental perspectives focus on normative changes in the anticipation of moral emotions, as well as discontinuities and constraints by inter-individual variation. Yet, most previous research has studied normative changes in empathy/sympathy thus far, and to a far more limited extent, in guilt feelings. Most other moral emotions have gone almost entirely unstudied thus far, and the few existing works have been limited to cross-sectional designs.

Based on the extant literature, three promising areas of future research can be identified: First, while much research has been conducted on the development of empathy/sympathy, the systematic developmental study of both negatively and positively valenced emotions from childhood to adulthood is still in its infancy. Thus, systematic longitudinal research on positively valenced and negatively valenced moral emotions is warranted. Normative change needs to be considered in relation to individual differences and within long-term perspectives. 
Second, research on relations between various emotions, such as sympathy, guilt, and pride, as well as developmental changes in these relations, may help to elucidate further how children and adolescents experience the affective consequences of morally salient situations. Third, innovative methodologies for the study of children's moral emotions are warranted. For example, researchers have begun to use narrative approaches to the study of moral emotion, which can reveal important information about how children construct their own emotional experiences in moral encounters (Gutzwiller-Helfenfinger, Gasser, \& Malti, 2010; Wainryb \& Recchia, 2012). Furthermore, incorporating cognitive measures, such as eye tracking, in conjunction with emotion recognition technology can help developmental scientists further understand the interaction between attentional mechanisms and affective responses in morally salient situations. Finally, atypical patterns of moral emotions and their developmental pathways may be an important goal for further investigation, as it may contribute to our causal understanding of psychopathology (Frick \& White, 2008). For example, extreme levels of guilt and altruism may be pathological (Oakley, Knafo, Madhavan, \& Wilson, 2011), as may be the absence of any emotion in contexts of moral conflict and transgression. More research in these areas will make a significant contribution to the further advancement of developmental theoretical accounts of moral emotions. 


\section{References}

Arsenio, W. (in press). Moral emotion attributions and aggression. In M. Killen \& J. Smetana (Eds.), Handbook of moral development (2 ${ }^{\text {nd }}$ Ed.). Mahwah, NJ: Lawrence Erlbaum.

Blair, R.J.R. \& Fowler, K. A. (2008). Moral emotions and moral reasoning from the perspective of affective cognitive neuroscience: A selective review. European Journal of Developmental Science, 2, 303-322.

Blasi, A. (1980). Bridging moral cognition and moral action: A critical review of the literature. Psychological Bulletin, 88, 1-45.

Carlo, G. (2006). Care-based and altruistically-based morality. In M. Killen, \& J. Smetana (Eds.), Handbook of moral development (pp.551-579). Mahwah, NJ: Lawrence Erlbaum.

Carpendale, J. I. M., \& Lewis, C. (2006). How children develop social understanding. Oxford: Blackwell Publishers.

Davidov, M., Zahn-Waxler, C., Roth-Hanania, R., \& Knafo, A. (2013). Concern for others in the first year of life: Theory, evidence, and avenues for future research. Child Development Perspectives, 7(2), 126-131.

Decety, J., Michalska, K.J., \& Kinzler, K.D. (2012). The contribution of emotion and cognition to moral sensitivity: a neurodevelopmental study. Cerebral Cortex, 22(1), 209-220. doi: 10.1093/cercor/bhr111

Dys, S.P., \& Malti, T. (2013). Children's spontaneous and self-reported emotions following moral transgressions. Manuscript in preparation.

Eisenberg, N. (2000). Emotion, regulation, and moral development. Annual Review of Psychology, 51(1), 665-697. doi: 10.1146/annurev.psych.51.1.665 
Eisenberg, N., Spinrad, T. L., \& Morris, A. (in press). Empathy-related responding in children. In M. Killen, \& J. Smetana (Eds.), Handbook of moral development ( $2^{\text {nd }}$ Ed.). Mahwah, NJ: Lawrence Erlbaum.

Ekman, P. \& Friesen, W. V. (1969). A tool for the analysis of motion picture film or video tape. American Psychologist, 24, 240-243.

Flack, J. C., \& de Waal, F. B. M. (2000). Any animal whatever? Darwinian building blocks of morality in monkeys and apes. Journal of Consciousness Studies, 7, 1-29.

Frick, P. J., \& White, S. F. (2008). The importance of callous-unemotional traits for developmental models of aggressive and antisocial behavior. Journal of Child Psychology and Psychiatry, 49(4), 359-375. doi: 10.1111/j.1469-7610.2007.01862.x

Gasser, L., \& Keller, M. (2009). Are the competent the morally good? Perspective taking and moral motivation of children involved in bullying. Social Development, 18, 798-816. doi: 10.1111/j.1467-9507.2008.00516.x

Gasser, L., Malti, T., \& Buholzer, A. (2013). Swiss children's moral and psychological judgments about inclusion and cxclusion of children with disabilities. Child Development. Advanced online publication. doi: 10.1111/cdev.12124

Gibbard, A. (1990). Wise choices, apt feelings: A theory of normative judgment. Cambridge, MA. Harvard University Press.

Gutzwiller-Helfenfinger, E., Gasser, L., \& Malti, T. (2010). Moral emotions and moral judgment in children's narratives: Comparing real-life and hypothetical transgressions. New Directions for Child and Adolescent Development, 129, 11-32. doi: 10.1002/cd.273

Hamlin, K., Wynn, K., \& Bloom, P. (2007). Social evaluation by preverbal infants. Nature, 450, 557-559. doi: 10.1038/nature06288 
Hoffman, M. L. (2000). Empathy and moral development. Implications for caring and justice. New York: Cambridge University Press.

Izard, C.E. (1994). Minimal cognitive prerequisites for emotion. In P. Ekman, \& R.J. Davidson (Eds.), The nature of emotion (pp. 356-361). New York: Oxford University Press.

Johnston, M. \& Krettenauer, T. (2011). Moral self and moral emotion expectancies as predictors of anti- and prosocial behavior in adolescence: A case for mediation? European Journal for Developmental Psychology, 8(2), 228-243. doi: $10.1080 / 17405621003619945$

Keller, M., Lourenço, S., Malti, T., \& Saalbach, H. (2003). The multifaceted phenomenon of "happy victimizers": A cross-cultural comparison of moral emotions. British Journal of Developmental Psychology, 21, 1-18. doi: 10.1348/026151003321164582

Killen, M. (2007). Children's social and moral reasoning about exclusion. Current Directions in Psychological Science, 16, 32-36. doi: 10.1111/j.1467-8721.2007.00470.x

Killen, M., Lee-Kim J., McGlothlin H., Stangor C. (2002). How children and adolescents evaluate gender and racial exclusion. Monographs of the Society for Research in Child Development, 67(4, Serial No. 271).

Killen, M., Mulvey, K. L., Richardson, C., Jampol, N., \& Woodward, A. (2011). The accidental transgressor: Morally-relevant theory of mind. Cognition, 119(2), 197-215. doi: 10.1016/j.cognition.2011.01.006

Knafo, A., \& Plomin, R. (2006). Prosocial behavior from early to middle childhood: Genetic and environmental influences on stability and change. Developmental Psychology, 42(5), 771-786. doi: 10.1037/0012-1649.42.5.771

Knafo, A., Zahn-Waxler, C., Van Hulle, C., Robinson, J. L., \& Rhee, S. H. (2008). The developmental origins of a disposition toward empathy: Genetic and environmental 
contributions. Emotion, 8(6), 737-752. doi:10.1037/a0014179

Kochanska, G., Barry, R.A., Jimenez, N.B., Hollatz, A.L., \& Woodard, J. (2009). Guilt and effortful control: Two mechanisms that prevent disruptive developmental trajectories. Journal of Personality and Social Psychology, 97(2), 322-333. doi: 10.1037/a0015471

Kohlberg, L. (1984). The psychology of moral development: Volume 2. Essays on moral development. New York: Harper and Row.

Krettenauer, T., \& Eichler, D. (2006). Adolescents' self-attributed emotions following a moral transgression: Relations with delinquency, confidence in moral judgment, and age. British Journal of Developmental Psychology, 24, 489-506. doi: 10.1348/026151005X50825

Krettenauer, T., Malti, T., \& Sokol, B. W. (2008). Development of moral emotions and the happy-victimizer phenomenon: A critical review of theory and application. European Journal of Developmental Science, 2, 221-235. doi: 10.3233/DEV-2008-2303

Lagattuta, K.H., \& Thompson, R. A. (2007). The development of self-conscious emotions: Cognitive processes and social influences. In J.L. Tracy, R.W. Robins, \& J. P. Tangney (Eds.), The self-conscious emotions: Theory and research (pp. 91-113). New York: Guilford.

Leslie, A. M., Knobe, J., \& Cohen, A. (2006). Acting intentionally and the side-effect effect: Theory of mind and moral judgment. Psychological Science, 17(5), 421-427. doi: 10.1111/j.1467-9280.2006.01722.x

Malti, T. (2013, in preparation). Toward an integrated clinical-developmental model of moral emotions in early and middle childhood. 
Malti, T., Eisenberg, N., Kim, H., \& Buchmann, M. (2013). Developmental trajectories of sympathy, moral emotion attributions, and moral reasoning: The role of parental support. Social Development. Advanced online publication. doi: 10.1111/sode.12031

Malti, T., Gummerum, M., Keller, M., \& Buchmann, M. (2009). Children's moral motivation, sympathy, and prosocial behavior. Child Development, 80, 442-460. doi: 10.1111/j.14678624.2009.01271.x

Malti, T., Gummerum, M., Keller, M., Chaparro, M.P., \& Buchmann, M. (2012). Early sympathy and social acceptance predict the development of sharing in children. PLoS ONE, 7(12), e52017. doi:10.1371/journal.pone.0052017

Malti, T., \& Keller, M. (2010). Development of moral emotions in cultural context. In W. Arsenio \& E. Lemerise (Eds.), Emotions, aggression, and morality in children: Bridging development and psychpathology (pp. 177-198). Washington, DC: American Psychological Association. doi:10.1037/12129-009

Malti, T., Keller, M., \& Buchmann, M. (2012). Do moral choices make us feel good? The development of adolescents' emotions following moral decision making. Journal of Research on Adolescence. 23(2), 389-397. doi: 10.1111/jora.12005

Malti, T., Killen, M., \& Gasser, L. (2012). Social judgments and emotion attributions about exclusion in Switzerland. Child Development, 83, 697-711. doi: 10.1111/j.14678624.2011.01705.x

Malti, T., \& Krettenauer, T. (2013). The relation of moral emotion attributions to prosocial and antisocial behavior: A meta-analysis. Child development, 84(2), 397-412. doi: 10.1111/j.1467-8624.2012.01851.x 
Malti, T., \& Latzko, B. (2012). Moral emotions. In V. Ramachandran (Ed.), Encyclopedia of human behavior ( $2^{\text {nd }}$ edition, pp. 644-649). Maryland Heights, MO: Elsevier. doi: 10.1016/B978-0-12-375000-6.00099-9

Malti, T., \& Ongley, S. F. (2013). The development of moral emotions and moral reasoning. In M. Killen \& J. Smetana (Eds.), Handbook of moral development (pp. 163-183). New York: Taylor \& Francis.

Nunner-Winkler, G., \& Sodian, B. (1988). Children's understanding of moral emotions. Child Development, 59, 1323-1338. doi: 10.2307/1130495

Nussbaum, M. (2001). Upheavals of thought: The intelligence of the emotions. Cambridge: Cambridge University Press.

Oakley, B., Knafo, A., Madhavan, G., \& Wilson, D. S. (Eds.). (2011). Pathological altruism. Oxford University Press, USA.

Oser, F. (2006). The "unhappy moralist" effect: Emotional conflicts between being good and being successful. In L. Verschaffel, F. Dochy, M. Boekaerts, \& S. Vosniadou (Eds.) Instructional psychology: Past, present and future trends (pp. 149-166). Amsterdam: Elsevier.

Piaget, J. (1932/1999). The moral development of the child. London: Kegan Paul.

Roth-Hanania, R., Davidov, M., \& Zahn-Waxler, C. (2011). Empathy development from 8 to 16 months: Early signs of concern for others. Infant Behavior \& Development, 34(3), 447-458. doi: 10.1016/j.infbeh.2011.04.007

Smetana, J. G. (2006). Social-cognitive domain theory: Consistencies and variations in children's moral and social judgments. In M. Killen \& J. Smetana (Eds.) Handbook of moral development, 119-153. Mahwah, NJ: Lawrence Erlbaum. 
Sinnot-Armstrong, W.P. (Ed.). (2008a). Moral psychology, volume 2: The cognitive science of morality. Cambridge: MIT Press.

Sinnot-Armstrong, W. P. (Ed.). (2008b). Moral psychology, volume 3: The neuroscience of morality. Cambridge: MIT Press.

Sokol, B. W. (2004). Children's conceptions of agency and morality: Making sense of the happy victimizer phenomenon. Unpublished doctoral dissertation, University of British Columbia, Vancouver, Canada.

Sokol, B. W. \& Chandler, M. J. (2003). Taking agency seriously in the theories-of-mind enterprise: Exploring children's understanding of interpretation and intention. British Journal of Educational Psychology Monograph Series II, 125-136.

Strohmeier, D., Malti, T., \& Killen, M. (2013). The role of bystander behavior on judgments and emotion attributions about social exclusion in Austrian schools. Manuscript in preparation.

Tangney, J. P., Stuewig, J., \& Mashek, D. J. (2007). Moral emotions and moral behavior. Annual Review of Psychology, 58, 345-372. doi:10.1146/annurev.psych.56.091103.070145

Tracy, J. L., Robins, R. W., \& Tangney, J. P. (2007). The self-conscious emotions: Theory and research. New York: Guilford Press.

Turiel, E. (1983). The development of social knowledge: Morality and convention. Cambridge: Cambridge University Press.

Wainryb, C., Brehl, B. A., \& Matwin, S. (2005). Being hurt and hurting others: Children's narrative accounts and moral judgments of their own interpersonal conflicts. Monographs of the Society for Research in Child Development, 70, 1-114. 
Wainryb, C., \& Recchia, H. E. (2012). Emotion and the moral lives of adolescents: Vagaries and complexities in the emotional experience of doing harm. New Directions for Youth Development, 136, 13-26. doi: 10.1002/yd.20035 